\title{
OBTAINING OF MODIFIED POLYAMIDE FROM THE SOLUTION
}

\author{
Natalia Chopyk ${ }^{1}$, Victoria Zemke ${ }^{1}$, Iryna Dovga ${ }^{1}$ \\ 1. Department of Chemical Technology Plastics Processing, Lviv Polytechnic National University, \\ 12 Bandery str., Lviv, UKRAINE. E-mail: viktoriia.m.zemke@lpnu.ua
}

\begin{abstract}
The optimal conditions for obtaining polymer nanocomposites based on organoclay and polyamide have been studied and determined.
\end{abstract}

Keywords - polyamide, montmorillonite, solvent, polyvinylpyrrolidone, precipitation.

\section{Introduction}

At the end of twentieth century, a group of scientists have obtained nanocomposites based on polyamide and layered silicates which has positively effected on the properties of PA-6 and significantly expanded areas of this polymer application. Obtaining of polymer nanocomposite is possible by the next methods: in solution, in the melt, in the process of polymer synthesis as well as the use of sol-gel process. The most interesting is the method of obtaining a polymer nanocomposite from the solution.

\section{Research results}

Polyamide, by its properties, is practically insoluble in ordinary solvents except the water (polar solvent). During the research we refused to apply the water due to its impact on the structure of the obtained complex.

Polyamide is soluble in formic acid in the range of concentrations from $77 \%$ to $90 \%$, but $85 \%$ showed itself the best.

It has been researched that for $85 \%$ of concentrated formic acid in a volume of $100 \mathrm{ml}, 15 \%$ of mass PA-6 is optimally dissolved. The process of complete dissolution of PA-6 in formic acid continues for $2 \ldots 3$ hours.

The next stage was adding of MPS complex into the composition (a mixture of montmorillonite with polyvinylpyrrolidone in the ratio MMT: PVP $=1: 5$ in the form of a fine powder) in amount of 5, 10, $20 \mathrm{wt} \%$. relatively to the mass of PA-6. Applying acetone as a solvent made it possible to precipitate the PA- 6 complex with the MPS but a large consumption of it was found. To reduce the consumption of acetone other possible solvents were analyzed and their optimal ratio was experimentally determined. Therefore, benzene was used as a co-solvent. The obtained mixture was precipitated with a solution of acetone and benzene (ratio of components 1: 1 $\mathrm{rpm}$ ). At the initial stage of precipitation $200 \mathrm{ml}$ of solution was applied. The obtained mixture was holded to settle for 15 minutes, followed by draining of the surface layer. Next step was reprecipitation via the solvents mixture in an amount of $100 \mathrm{ml}$. The precipitate formed was filtered off with a water pump and dried in a vacuum oven at $80{ }^{\circ} \mathrm{C}$ for 8 hours with further raising the temperature to $105^{\circ} \mathrm{C}$.

\section{Conclusion}

Consequently, the conducted studies made it possible to obtain a nanocomposite based on PA6 and MPS from the solution which determined positive effect on the properties of PA-6. The developed composites are characterized by the manufacturability inherent in thermoplastics as well as may be respective for the manufacture of structural products by injection molding. 